\title{
The Application of Umbilical Cord Blood Cells in the Treatment of Diabetes Mellitus
}

\author{
Tomas Koblas ${ }^{1}$, S. Mitchell Harman ${ }^{2}$ and Frantisek Saudek ${ }^{1}$
}

\begin{abstract}
${ }^{1}$ Laboratory of Pancreatic Islets, Institute for Clinical and Experimental Medicine, Center for Cell Therapy and Tissue Repair, Prague, Czech Republic. ${ }^{2}$ Kronos Longevity Research Institute, Phoenix, AZ, USA. Address correspondence to: Frantisek Saudek, e-mail:frantisek.saudek@medicon.c\%:
\end{abstract}

\section{Abstract}

In recent years, human umbilical cord blood (HUCB) has emerged as an attractive tool for cell-based therapy. Although at present the clinical application of HUCB is limited to the fields of hematology and oncology, a rising number of studies show potential for further application in the treatment of non-hematopoietic diseases. HUCB, with its real abundance, simple collection procedure and no serious ethical dilemmas, represents a valuable alternative to the use of

\section{Introduction}

$\oint^{n}$ spite of recent advances in diabetes care, chronic hyperglycemia persists despite all the available means of insulin therapy, causing serious long-term complications in most patients. Pancreas or islet transplantation are the only methods available to date which are able to establish long-term normoglycemia or nearnormoglycemia. Due to the potential side effects of immunosuppressive drugs, their use remains restricted to subjects in whom a simultaneous transplantation of the kidney is needed or to those with impaired glycemic control who are at a high risk of hypoglycemic episodes on insulin therapy. Should the risks of the surgical procedure and chronic immunosuppression improve, there is still an enormous discrepancy between the availability of suitable pancreatic grafts for organ or islet transplantation and the number of dia- other stem cell sources. The aim of this article is to review the literature on HUCB and to assess its eventual usability in the treatment of diabetes mellitus. This review presents some recent reports concerning pancreatic endocrine stem cells and their identification, HUCB stem cells and their advantages and, finally, the potential for converting HUCBderived stem cells into insulin-producing $\beta$-cells.

Keywords: diabetes $\cdot$ umbilical cord blood $\cdot$ differentiation $\cdot \beta$-cells

betic subjects who could profit from transplant therapy.

The hope of obtaining an unlimited supply of insulin-producing tissue revived after the first reports on successful isolation of human embryonic and specific adult stem cells emerged $[1,2]$. These cells were able to proliferate and differentiate into various cell types including those bearing a phenotype of insulin-secreting $\beta$-cells [3-7]. Although these pioneering works have initiated intensive research, the progress made to date has been insufficient for the clinical application of a cell-based therapy for diabetes. The fundamental question in this field remains as to which of the potential cell types will be the most suitable for therapy. Apart from uncertainty concerning their real plasticity and safety, most of the cell types still have drawbacks due to ethical and immunological problems arising from their biological source. In this respect, stem cell-rich 
umbilical cord blood represents a promising and so far inadequately studied therapeutic tool.

\section{Human umbilical cord blood}

The umbilical cord serves as a route for the transport of nutrients and oxygen between mother and fetus. Although at first sight it could appear that umbilical cord blood differs from the rest of the infant's blood, the term umbilical cord blood only describes blood remaining in the cord after birth. The blood may be harvested from the cord and cryopreserved for further processing.

In the past, HUCB samples have usually been discarded following birth. However, this situation may change in the near future, as a growing number of reports demonstrated a greater potential of cells present in HUCB. Umbilical cord blood is known as a rich source of hematopoietic stem cells (HSC) [8, 9], which makes it a valuable alternative to bone marrow (BM) transplantation in hematology and oncology. Although cord blood is mainly used for the treatment of malignant and genetic blood diseases, the therapeutic potential of HUCB cells can go beyond blood system therapy. In addition to the HSC, a variety of different stem cell types have been identified within HUCB. Mesenchymal stem cells (MSC) [10], endothelial stem cells (ESC) [11] and a not yet fully characterized population of multipotent cells can be found in the cord blood. Although these multipotent stem cells are very rare and may differentiate into a limited number of cell types, they may represent a promising tool for cell therapy.

\section{Advantages of HUCB as a source for stem cell therapy}

HUCB as a source of stem cells has a number of significant advantages over other stem cell sources. First of all, non-invasive collection without any risk for the donor and a real abundance with more than 100 million births annually worldwide make the HUCB a readily available source of stem cells. Furthermore, a rising number of public and private banks, which can store huge quantities of cord blood units, allow an optimal HLA match for the allogeneic or potentially autologous transplantation. Last but not least, HUCB stem cells, unlike the more controversial embryonic stem cells, do not involve ethical issues. Thus, HUCB has now emerged as an attractive source of stem cells for research and clinical application in treating a variety of diseases.
The biological advantages of HUCB stem cells are even more apparent. Cord blood is collected immediately after the baby is born, which means that HUCB stem cells are among the youngest types of cell that can be isolated from a human being. This is important, as cells from adult donors may have an impaired DNA quality caused by environmental and endogenous factors during their lifetime. Moreover, the HUCB cells carry a lower risk of viral contamination due to the minimal exposure of donor babies to viruses during prenatal life $[12,13]$.

One of the main advantages of HUCB cells is hidden in their core. The potential of normal cells to replicate is determined by the length of telomeres, the sequences of the DNA at the chromosome ends. The telomeres abbreviate with each cycle of cell division and critically short telomeres finally lead to cell arrest or cell death. HUCB stem cells have very long telomeres as they undergo a limited number of cell divisions prior to birth. The length of HUCB cell telomeres is 11-13 kbp, compared with 8-9 $\mathrm{kbp}$ in $\mathrm{BM}$ cells of 16-59 year old donors [14]. Moreover, HUCB stem cells contain telomerase, the enzyme which elongates telomeres. Thus, telomere-shortening caused by cell replication is further decreased in cells from HUCB [15].

A critical disadvantage that HUCB has in common with other allogeneic cell-based therapies is the potential to induce graft-versus-host disease (GVHD), which may develop as a result of immune cell transplantation to the recipient. This complication is usually seen in $\mathrm{BM}$ transplantations (BMT) even if a high degree of HLA match is achieved. However, compared to BMT, the incidence of GVHD is lower in HUCB transplantation, which could be due to the lower number of Tcells, immaturity of B-cells and decreased function of dendritic cells. As a concomitant strategy, the depletion of lymphocytes and other immune cells could further limit the incidence of GVHD [16]. However, the elimination of some immune cells may impair the establishment of cell chimerism, which is speculated to be a crucial mechanism for the achievement of a long lasting tolerance of the host immune system to transplanted cells.

\section{Cord blood-derived stem cells}

The potential of HUCB stem cells for the treatment of non-hematopoietic diseases is certainly limited by the presence of multipotent stem cells within the cord blood. Several studies have already shown that HUCB indeed contains stem cells that can differentiate into multiple cell types. The unrestricted somatic stem 
cell (USSC) has recently emerged as the most promising candidate for such multipotent stem cells [17]. In spite of a very low frequency in cord blood, USSC can easily be expanded without spontaneous differentiation to at least $10^{15}$ cells, while retaining a normal karyotype. Under appropriate culture conditions, USSC are able to turn into many types of cells with characteristics of osteoblasts, chondroblasts, adipocytes, neural precursors and hematopoietic cells in a homogeneous fashion. Upon transplantation, USSC differentiated into the same cell types with the absence of cell fusion. The proliferative potential of USSC was confirmed by a high number of culture passages and a decreased shortening of telomeres.

Another candidate for multipotent HUCB stem cells is a lineage-restricted cell subset that bears the markers of embryonic stem cells [18]. These so-called "cord-blood-derived embryonic-like stem cells" (CBEs) can expand hematopoietic progenitors and differentiate into hepatocytes and neuroglial progenitors [19]. CBEs as well as USSC comprise a small subpopulation of HUCB cells with no more than $0.25 \%$ of total HUCB cells (Table 1).

Due to the facts that (a) different cell markers have been determined and (b) different isolation and cultivation conditions have been applied in experiments, it is still questionable whether USSC and CBEs are two distinct stem cell populations or whether they are only subsets of each other. At least one difference between these two populations is that USSC have a higher self- renewal capacity than CBEs. On the other hand, the multilineage differentiation capacity of USSC and CBEs is very similar and appears to be determined by the presence of cells with almost the same differentiation potential.

\section{Sources of pancreatic stem cells in the regene- rating organism}

During postnatal life, the loss of $\beta$-cell mass due to apoptosis is compensated by the replication of existing $\beta$-cells and the formation of new $\beta$-cells from stem/progenitor cells. Although the concept of $\beta$-cell regeneration from postnatal stem cells has recently been challenged [20], it remains very likely that stem cells differentiate into insulin-producing cells even in adult life. Because the pancreatic stem cell has not yet been fully characterized, the precise origin of these cells is not known. The main sources of such stem cells are thought to be specific pancreatic duct cells and islet cells themselves [21]. Nevertheless, cells with a potential to differentiate toward insulin-producing cells have also been identified in organs other than the pancreas, such as the spleen [22], liver [7] and BM [23]. Moreover, insulin-producing cells were found within the same organs and adipose tissue in diabetic animals [24].

The exact mechanism by which BM-derived cells become insulin-producing cells is not clear. Authors of an in vivo study ruled out that cells adopting a $\beta$-cell-like

Table 1. Comparison of HUCB-derived cells and pancreatic progenitor cells identified so far

\begin{tabular}{|c|c|c|c|c|c|}
\hline \multirow[t]{2}{*}{ Property } & \multicolumn{3}{|c|}{ Cord blood-derived cells } & \multicolumn{2}{|c|}{ Pancreas-derived cells } \\
\hline & HUCB & USSC & $\mathrm{CBE}$ & MPP & PMP \\
\hline Self-renewal capacity & +++ & +++ & ++ & + & + \\
\hline $\begin{array}{l}\text { Differentiation into mul- } \\
\text { tiple cell types }\end{array}$ & & $\begin{array}{c}\text { Hematopoietic, hepato- } \\
\text { cytes, osteoblasts, chon- } \\
\text { droblasts, adipocytes and } \\
\text { neural cells }\end{array}$ & $\begin{array}{l}\text { Hematopoietic, } \\
\text { hepatocytes and } \\
\text { neuroglial pro- } \\
\text { genitors }\end{array}$ & $\begin{array}{l}\text { Endocrine acinar } \\
\text { and ductal pancre- } \\
\text { atic cells }\end{array}$ & $\begin{array}{l}\text { Endocrine aci- } \\
\text { nar, stellate } \\
\text { pancreatic, } \\
\text { neurons, glial } \\
\text { cells }\end{array}$ \\
\hline $\begin{array}{l}\text { Expression of stem cell } \\
\text { markers }\end{array}$ & $\begin{array}{l}\text { Oct-4, SSEA-3, SSEA-4, } \\
\text { Tra 1-60, Tra 1-81, Rex- } \\
\text { 1, Sox-1, Sox-2, FGF-4 }\end{array}$ & Not done & $\begin{array}{l}\text { Oct-4, SSEA-3, } \\
\text { SSEA-4, Tra 1-60, } \\
\text { Tra 1-81 }\end{array}$ & Not done & Not done \\
\hline $\begin{array}{l}\text { Markers of pancreatic } \\
\text { precursor cells }\end{array}$ & $\begin{array}{c}\text { Ngn-3, nestin, Pax-4, Isl- } \\
1\end{array}$ & Negative & Not done & $\begin{array}{l}\text { Ngn-3, } \\
\text { nestin, } \\
\text { PDX-1 }\end{array}$ & $\begin{array}{l}\text { Ngn-3, nestin, } \\
\text { PDX-1 }\end{array}$ \\
\hline $\begin{array}{l}\text { Markers of oval stem } \\
\text { cells }\end{array}$ & $\begin{array}{l}\text { CK-18, CK-19, } \\
\alpha \text {-fetoprotein, } \\
\text { albumin }\end{array}$ & CK-18 & $\begin{array}{c}\text { CK-18, } \\
\alpha \text {-fetoprotein, } \\
\text { albumin }\end{array}$ & $\begin{array}{c}\text { CK-18, } \\
\alpha \text {-fetoprotein, } \\
\text { albumin }\end{array}$ & Not done \\
\hline
\end{tabular}

Legend: Self-renewal capacity is defined as follows: + : less than $10^{6}$-fold increase. ++ : $10^{6}-10^{15}$-fold increase. +++ : more then $10^{15}$-fold increase in cell number. MPP: multipotent pancreatic progenitors. PMP: pancreas derived multipotent precursors. 
phenotype could emerge through cell fusion. Their assumption is supported by in vitro studies [25,26], which also preclude fusion of BM cells with differentiated $\beta$ cells.

The transdifferentiation or dedifferentiation of committed hematopoietic stem cells (HSCs) is one possible explanation. A second explanation is based on the presence of cells with the differentiation capabilities of embryonic stem cells. Recently identified multipotent adult progenitor cells (MAPCs) isolated from $\mathrm{BM}$ with their multilineage differentiation and selfrenewal potential may represent such a type of cells [2]. Another hypothesis postulates that multiple tissuespecific stem cells reside within the BM and the circulation. Upon the release of specific cytokines and

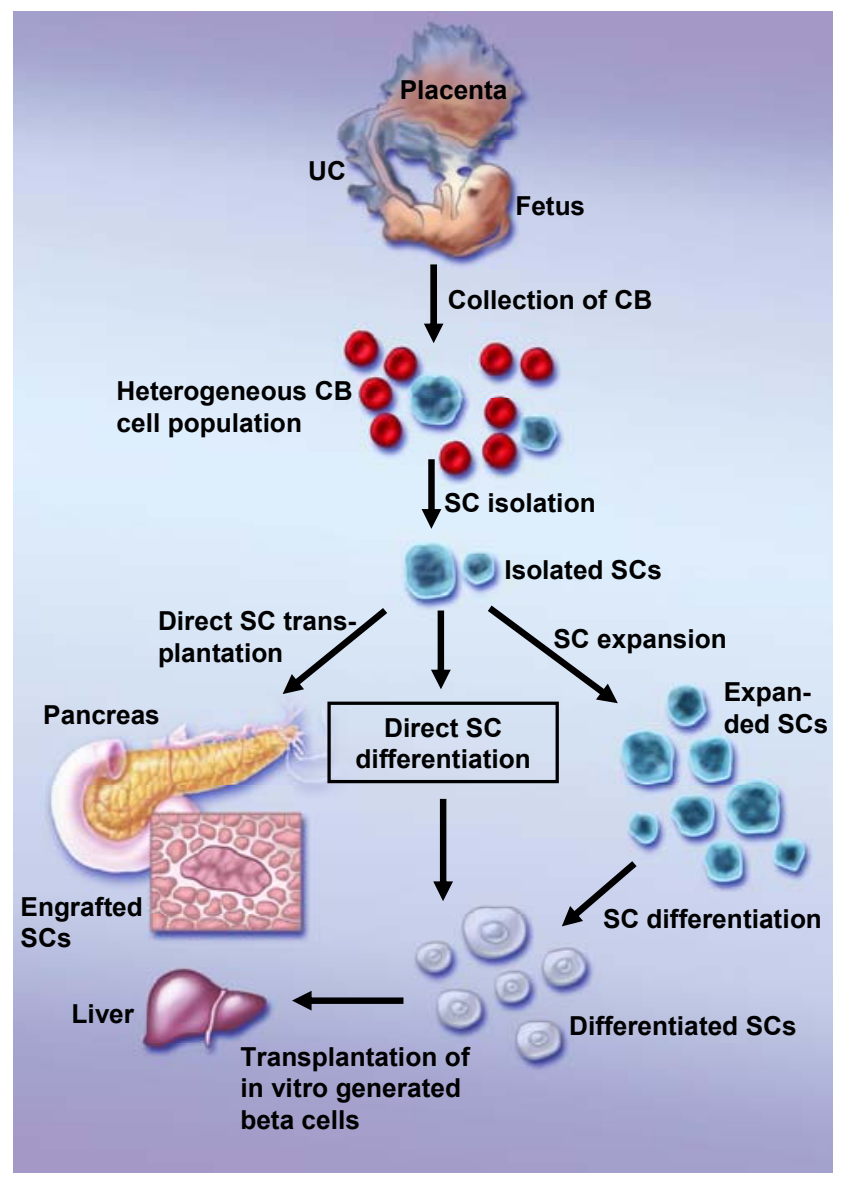

Figure 1. Possible methods of generating HUCB-derived $\boldsymbol{\beta}$-cells. After isolation of a specific stem cell population three alternative approaches are possible to obtain mature $\beta$-cells: a) direct transplantation of not manipulated stem cells and their homing to the pancreas with their subsequent differentiation, b) in vitro differentiation of isolated stem cells and their transplantation to the liver, c) expansion of stem cells prior to their differentiation and transplantation. UC: umbilical cord. CB: cord blood. SC: stem cell. growth factors, these cells may migrate to related tissue and differentiate into the required cell type.

\section{HUCB for diabetes treatment}

In conjunction with the application of HUCB for diabetes treatment, the observation that BM-derived cells may become insulin-producing cells is of enormous importance. Since the HUCB and BM contain similar cell populations and HUCB-derived USSC share most of the cell markers and properties with MAPCs, it should be considered that HUCB may contain cells with a potential to develop into insulinproducing cells (Table 1 ).

The identification of adult endocrine pancreatic progenitors is a very hard task. Markers involved in endocrine pancreas development and $\beta$-cell neogenesis are widely used for this purpose. Hitherto, one study carried out by Pessina and colleagues has investigated the expression of endocrine pancreatic progenitor markers in HUCB cells [27]. They found that undifferentiated HUCB cells were positive for nestin, cytokeratin 19 and transcription factors, such as neurogenin-3 (Ngn-3), Pax-4 and Isl-1, which are considered to be important for $\beta$-cell differentiation (Table 1). Since the controversial marker nestin and the detected transcription factors are also expressed by neural cells and their progenitors, which have already been found in HUCB [28], the detection of these markers is not surprising. Moreover, the evidence that HUCB does not contain pancreatic precursors was confirmed, since the expression of the PDX-1 gene, one of the key transcription factors of pancreatic precursors, was not detected.

Although it is not likely that HUCB contains pancreatic progenitors, it is possible that HUCB stem cells are able to differentiate toward pancreatic cells. The candidates for the endocrine pancreatic precursor have a similar phenotype with hepatic [29] and neural [30] stem cells, which could already be reproduced from HUCB cells $[28,31]$. Therefore, further in vitro or in vivo manipulation could result in the differentiation of HUCB cells into pancreatic cells (Figure 1). However, this ability must be proven in further experiments.

Partial clarification of this question has arisen from a few in vivo studies which investigated the effect of HUCB transplantation in diabetic animals. One of them indicated that transplantation of HUCB cells resulted in the improvement of blood glucose levels and the survival of diabetic mice. Furthermore, a regression of glomerular hypertrophy and tubular dilatation, common complications attributed to diabetes, was ob- 
served in HUCB-treated mice [32]. In another study, transplantation of HUCB cells into type 1 diabetic mice delayed the onset of autoimmunity and insulitis and improved blood glucose levels. The authors reported that the transplanted mice did not show any clinical or histological evidence of GVHD, despite the omission of immunosuppressive therapy [33]. Because the persistence of human cells was confirmed only in the spleens of a few mice and due to the fact that human cells could not be detected in the pancreas or other organs, it remains unclear which mechanism engenders the improvements that have been achieved.

Finally, a recent report has focused on the capability of HUCB to generate insulin-producing cells in vivo [34]. Following the intravenous transplantation of HUCB into NOD/SCID mice, insulin-producing cells of human origin were found in mouse islets. Although the human origin and the insulin-producing potential of the identified cells are almost indisputable, the mechanism underlying their transformation remains questionable. Insulin-producing cells containing both human and mouse chromosomes, as well as only human chromosomes, were identified using speciesspecific probes. Based on these results, the authors suggested that the generation of HUCB-derived insulin-producing cells can be mediated through both fusion-dependent and -independent mechanisms.

The number of HUCB cells that transdifferentiated and the rate of such an event are critical aspects. The proportion of HUCB-derived insulin-producing cells per total number of islet cells was $0.65 \%$, which was less than in the case of BM-derived insulin-producing cells [23]. However, it is worth noting that the animals were not diabetic after treatment in both experiments. Under diabetic conditions, the demand for the neogenesis of insulin-producing cells might be increased and the higher rate of HUCB cell differentiation could be a compensatory effect in the regeneration of $\beta$-cell mass.

Another line of evidence suggesting that HUCB may differentiate toward insulin-producing cells comes from reports on HUCB differentiation into hepatocyte-like cells (Table 1). The liver and the pancreas are derived from an endodermal lineage and share a lot of functional and developmental similarities. During development, the liver and ventral pancreas are formed from the same part of the endoderm. Therefore, it is not surprising that endoderm contains bipotential precursor cell populations for the development of these organs. Interestingly, the default fate of this common endoderm region is to activate the pancreas development program. However, the signals from cardiac mesoderm induce development of the liver instead of the pancreas in the major portion of this region [35]. Thus, the generation of endodermal progenitors or eventually liver/pancreas bipotential precursor cells could be one of the first steps in the differentiation of HUCB stem cells into insulin-producing cells from any multipotent stem cell.

Not only was the potential of HUCB cells to differentiate towards cells of endodermal origin proven by the detection of functional human hepatocytes in the liver of the USSC-transplanted animals [17], it could also be observed in other experiments. In vitro cultivation of unmanipulated HUCB cells in the presence of specific growth factors resulted in the generation of cells with a hepatocyte-like phenotype [31]. The same result could be achieved by the differentiation of CBEs after previous expansion [18] (Figure 1). It is worth noting in this context that hepatocyte-like cells derived in all of these studies expressed albumin, cytokeratin 18 and alpha-fetoprotein, which are regarded as markers of hepatic oval stem cells. Although hepatic oval stem cells reside within the liver and mainly contribute to liver regeneration, they may transdifferentiate into bile duct cells, myocytes and even into the cells of endocrine pancreas [7]. The transdifferentiation of hepatic oval stem cells into pancreatic endocrine cells, including insulin-producing cells, is another potential bridge on the route from HUCB stem cells to the pancreatic $\beta$-cell island (Figure 1).

The effect of HUCB cells in the treatment of various diseases, such as myocardial infarction, CNS and spinal cord injuries [36-38], has already been proven. We can conclude from most of these reports that the beneficial effect is supposed to be mediated by the indirect participation of HUCB cells in the regenerating process. HUCB cells are able to secrete mediators critical for the migration, proliferation and homing of endogenous progenitors and participate in a neovascularization of injured or ischemic tissue. While the majority of mediators are produced by mesenchymal cells derived from MSC, the neovascularization is achieved by the proliferation of endothelial cells derived from ESC.

Diabetic neuropathy is one of the most frequent complications in diabetes. Potential factors that may lead to this complication are insufficient nerve blood flow and a decreased amount of vessels around the peripheral nerves. Based on a recent study that employed HUCB-derived EPCs in order to reverse diabetic neuropathy, HUCB can be considered as a possible option for the treatment of this complication [39]. The injection of HUCB-derived EPCs into the legs of diabetic 
mice improved nerve function and blood flow at the injected side compared with the untreated legs.

As mentioned above, the reversal of other diabetic complications, such as glomerular hypertrophy and tubular dilatation, could be observed after transplantation of HUCB cells. However, it is not evident whether this effect was due to a decrease in blood glucose levels or due to the trophic influence of HUCB.

\section{Clinical application and possible approaches}

Different strategies should be considered for the clinical application of HUCB in the treatment of diabetes, since many factors may affect the whole procedure. However, the most crucial steps are well documented and will be determinative for the successful application of this therapeutic approach. They include the isolation of suitable cell populations and subsequent differentiation towards a $\beta$-cell phenotype. With regard to studies published so far, the problem of cell isolation appears to be almost resolved. Identification and selection of specific cell types based on surface markers and the array of in vitro manipulation procedures may lead to the generation of a homogenous population of multipotent cells. Cells with a potential to differentiate into endoderm-derived hepatocytes may represent starting material for further manipulation.

With respect to the high number of islet $\beta$-cells required for a single patient and the low frequency of multipotent stem cells in HUCB, in vitro expansion prior to transplantation appears to be necessary. Moreover, it is important to consider that this therapy will mainly be used in young patients. The ability of HUCB cells to multiply in vivo and in vitro appears to be satisfactory for the generation of a sufficient number of cells and their maintenance during the patient's life. Therefore, the most challenging task will be to direct the cell fate toward a $\beta$-cell phenotype. There are two strategies that are worth testing. The more simple approach is the direct transplantation of cultivated stem cells or partially differentiated precursor cells. HUCB cells have the capacity to migrate to various tissues and could be applied for this purpose. However, the exact mechanisms that drive the homing of manipulated cells in the pancreas and determine the phenotype of the potentially engrafted cells are not yet known.

An alternative approach may be the in vitro generation of pancreatic precursors or mature $\beta$-cells. The employment of exogenous factors that have been shown to be effective in $\beta$-cell differentiation could provide desirable outcomes. The main drawback of this approach is that the obtained cells could not be transplanted into the pancreas. Thus, the restoration of pancreatic $\beta$-cell mass as the most optimal scenario would not be achieved.

\section{Conclusion}

In the future, umbilical cord blood may be used as a therapeutic tool in the treatment of many diseases. The usability of HUCB in diabetes therapy depends on the ability of its cells to develop into insulin-producing $\beta$-cells, as well as on the respective research effort. As HUCB-derived cells have shown the potential to differentiate into insulin-producing cells, further goals include the identification of the suitable cell population and the development of methods for the differentiation of HUCB stem cells into insulin-producing $\beta$-cells. Successful achievements of this goal might result in the wide-scale production of $\beta$-cells and thus the treatment of diabetes. Although, at the present time, research on UCB stem cells for a potential treatment of diabetes is still in its early stages, we believe that the evidence we have presented here gives some reason for optimism. Acknowledgment: This work was supported by a grant: NR/8031-3/2004 from IGA of the Ministry of Health, Czech Republic.

\section{References}

1. Thomson JA, Itskovitz-Eldor J, Shapiro SS, Waknitz MA, Swiergiel JJ, Marshall VS, Jones JM. Embryonic stem cell lines derived from human blastocysts. Science 1998. 282:11451147.

2. Jiang Y, Jahagirdar BN, Reinhardt RL, Schwartz RE, Keene CD, Ortiz-Gonzalez XR, Reyes M, Lenvik T, Lund T, Blackstad M, et al. Pluripotency of mesenchymal stem cells derived from adult marrow. Nature 2002. 418:41-49.

3. Soria B, Roche E, Berna G, Leon-Quinto T, Reig JA, Martin F. Insulin-secreting cells derived from embryonic stem cells normalize glycemia in streptozotocin-induced diabetic mice. Diabetes 2000. 49:157-162.

4. Lumelsky N, Blondel O, Laeng P, Velasco I, Ravin R, McKay R. Differentiation of embryonic stem cells to insulin- secreting structures similar to pancreatic islets. Science 2001. 292:1389-1394.

5. Bonner-Weir S, Taneja M, Weir GC, Tatarkiewicz K, Song KH, Sharma A, O'Neil JJ. In vitro cultivation of human islets from expanded ductal tissue. Proc Natl Acad Sci U S A 2000. 97:7999-8004.

6. Zulewski H, Abraham EJ, Gerlach MJ, Daniel PB, Moritz W, Muller B, Vallejo M, Thomas MK, Habener JF. Multipotential nestin-positive stem cells isolated from adult pancreatic islets differentiate ex vivo into pancreatic endocrine, exocrine, and hepatic phenotypes. Diabetes 2001. 50:521-533.

7. Yang L, Li S, Hatch H, Ahrens K, Cornelius JG, Petersen BE, Peck AB. In vitro trans-differentiation of adult hepatic stem cells into pancreatic endocrine hormone-producing cells. Proc Natl Acad Sci U S A 2002. 99:8078-8083.

8. Broxmeyer HE, Douglas GW, Hangoc G, Cooper S, Bard 
J, English D, et al. Human umbilical cord blood as a potential source of transplantable hematopoietic stem/progenitor cells. Proc Natl Acad Sci U S A 1989. 86:3828-3832.

9. Mayani H, Lansdorp PM. Biology of human umbilical cord blood-derived hematopoietic stem/progenitor cells. Stem Cells 1998. 16:153-165.

10. Bieback K, Kern S, Kluter H, Eichler H. Critical parameters for the isolation of mesenchymal stem cells from umbilical cord blood. Stem Cells 2004. 22:625-634.

11. Murohara T, Ikeda $\mathbf{H}$, Duan J et al. Transplanted cord blood-derived endothelial precursor cells augment postnatal neovascularization. J Clin Invest 2000. 105:1527-1536.

12. Rubinstein P, Carrier C, Scaradavou A, et al. Outcomes among 562 recipients of placental-blood transplants from unrelated donors. N Eng J Med 1998. 339:1565-1577

13. Behzad-Behbahani A, Pouransari R, Tabei SZ, Rahiminejad MS, Robati M, Yaghobi R, Nourani H, Ramzi MM, Farhadi-Andarabi A, Mojiri A, et al. Risk of viral transmission via bone marrow progenitor cells versus umbilical cord blood hematopoietic stem cells in bone marrow transplantation. Transplant Proc 2005. 37:3211-3212.

14. Vaziri H, Dragowska W, Allsopp RC, Thomas TE, Harley CB, Lansdorp PM. Evidence for a mitotic clock in human hematopoietic stem cells: loss of telomeric DNA with age. Proc Natl Acad Sci U S A 1994. 91:9857-9860.

15. Gammaitoni L, Weisel KC, Gunetti M, Wu KD, Bruno S, Pinelli S, Bonati A, Aglietta M, Moore MA, Piacibello W. Elevated telomerase activity and minimal telomere loss in cord blood long-term cultures with extensive stem cell replication. Blood 2004. 103:4440-4448.

16. Grewal SS, Barker JN, Davies SM, Wagner JE. Unrelated donor hematopoietic cell transplantation: marrow or umbilical cord blood? Blood 2003. 101:4233-4244.

17. Kogler G, Sensken S, Airey JA, Trapp T, Muschen M, Feldhahn N, Liedtke S, Sorg RV, Fischer J, Rosenbaum C, et al., A new human somatic stem cell from placental cord blood with intrinsic pluripotent differentiation potential. $J$ Exp Med 2004. 200:123-135.

18. McGuckin CP, Forraz N, Baradez MO, Navran S, Zhao J, Urban R, Tilton R, Denner L. Production of stem cells with embryonic characteristics from human umbilical cord blood. Cell Prolif 2005. 38:245-255.

19. McGuckin CP, Forraz N, Allouard Q, Pettengell R. Umbilical cord blood stem cells can expand hematopoietic and neuroglial progenitors in vitro. Exp Cell Res 2004. 295:350-359.

20. Dor Y, Brown J, Martinez OI, Melton DA. Adult pancreatic beta-cells are formed by self-duplication rather than stem-cell differentiation. Nature 2004. 429:41-446.

21. Guz Y, Nasir I, Teitelman G. Regeneration of pancreatic beta-cells from intra-islet precursor cells in an experimental model of diabetes. Endocrinology 2001. 142:4956-4968.

22. Kodama S, Kuhtreiber W, Fujimura S, Dale EA, Faustman DL. Islet regeneration during the reversal of autoimmune diabetes in NOD mice. Science 2003. 302:1223-1227.

23. Ianus A, Holz GG, Theise ND, Hussain MA. In vivo derivation of glucose competent pancreatic endocrine cells from bone marrow without evidence of cell fusion. J Clin Invest 2003. 111:843-850.

24. Kojima H, Fujimiya M, Matsumura K, Nakahara T, Hara M, Chan L. Extrapancreatic insulin-producing cells in multiple organs in diabetes. Proc Natl Acad Sci U S A 2004. $101: 2458-2463$
25. Tang DQ, Cao LZ, Burkhardt BR, Xia CQ, Litherland SA, Atkinson MA, Yang LJ. In vivo and in vitro characterization of insulin-producing cells obtained from murine bone marrow. Diabetes 2004. 53:1721-1732.

26. Oh SH, Muzzonigro TM, Bae SH, LaPlante JM, Hatch HM, Petersen BE. Adult bone marrow-derived cells transdifferentiating into insulin-producing cells for the treatment of type I diabetes. Lab Invest 2004. 84:607-617.

27. Pessina A, Eletti B, Croera C, Savalli N, Diodovich C, Gribaldo L. Pancreas developing markers expressed on human mononucleated umbilical cord blood cells. Biochem Biophys Res Commun 2004. 323:315-322.

28. Buzanska L, Machaj EK, Zablocka B, Pojda Z, Domanska-Janik K. Human cord blood-derived cells attain neuronal and glial features in vitro. J Cell Sci 2002. 115:2131-2138.

29. Suzuki A, Nakauchi H, Taniguchi H. Prospective isolation of multipotent pancreatic progenitors using flow-cytometric cell sorting. Diabetes 2004. 53:2143-52.

30. Seaberg RM, Smukler SR, Kieffer TJ, Enikolopov G, Asghar Z, Wheeler MB, Korbutt G, van der Kooy D. Clonal identification of multipotent precursors from adult mouse pancreas that generate neural and pancreatic lineages. Nat Biotechnol 2004. 22:1115-1124.

31. Kakinuma S, Tanaka Y, Chinzei R, Watanabe M, Shimizu-Saito K, Hara Y, Teramoto K, Arii S, Sato C, Takase $\mathbf{K}$, et al. Human umbilical cord blood as a source of transplantable hepatic progenitor cells. Stem Cells 2003. 21:217-227.

32. Ende N, Chen R, Reddi AS. Transplantation of human umbilical cord blood cells improves glycemia and glomerular hypertrophy in type 2 diabetic mice. Biochem Biophys Res Commun 2004. 321:168-171.

33. Ende N, Chen R, Reddi AS. Effect of human umbilical cord blood cells on glycemia and insulitis in type 1 diabetic mice. Biochem Biophys Res Commun 2004. 325:665-669.

34. Yoshida S, Ishikawa F, Kawano N, Shimoda K, Nagafuchi S, Shimoda S, Yasukawa M, Kanemaru T, Ishibashi H, Shultz LD, et al. Human cord blood--derived cells generate insulin-producing cells in vivo. Stem Cells 2005. 23:14091416.

35. Deutsch G, Jung J, Zheng M, Lora J, Zaret KS. A bipotential precursor population for pancreas and liver within the embryonic endoderm. Development 2001. 128:871-881.

36. Kim BO, Tian H, Prasongsukarn K, Wu J, Angoulvant D, Wnendt S, Muhs A, Spitkovsky D, Li RK. Cell transplantation improves ventricular function after a myocardial infarction: a preclinical study of human unrestricted somatic stem cells in a porcine model. Circulation 2005. 112:96-104.

37. Sanberg PR, Willing AE, Garbuzova-Davis S, Saporta S, Liu G, Sanberg CD, Bickford PC, Klasko SK, El-Badri NS. Umbilical cord blood-derived stem cells and brain repair. Ann N Y Acad Sci 2005. 1049:67-83.

38. Kang KS, Kim SW, Oh YH, Yu JW, Kim KY, Park HK, Song $\mathbf{C H}$, Han H. A 37-year-old spinal cord-injured female patient, transplanted of multipotent stem cells from human UC blood, with improved sensory perception and mobility, both functionally and morphologically: a case study. Cytotherapy 2005.7:368-373.

39. Naruse K, Hamada Y, Nakashima E, Kato K, Mizubayashi R, Kamiya H, Yuzawa Y, Matsuo S, Murohara T, Matsubara $\mathbf{T}$, et al. Cord blood stem cells: Therapeutic neovascularization using cord blood-derived endothelial progenitor cells for diabetic neuropathy. Diabetes 2005. 54:1823-1828. 